\title{
DYNAMICS OF VALUES IN AMERICAN ELECTION DISCOURSE
}

\author{
Inna V. Kononova \\ Saint Petersburg State University of Economics, Saint Petersburg, Russia \\ Tatiana A. Melnichuk \\ M.K. Ammosov North-Eastern Federal University, Yakutsk, Russia
}

\begin{abstract}
The article presents the results of a corpus-based analysis of axiological characteristics of political discourse. Applying the method of identifying keywords in a corpus the authors described the dynamics of the American election discourse dominant values in the period from 1952 to 2016. The research material comprised the texts of American presidential election commercials from seventeen campaigns. The texts were compiled into three corpora according to three historical periods: period I - 1952-1972; period II - 1976-2000; period III - 2004-2016. It was found that the invariant values represented in the texts of election commercials of all the historical periods are: "prosperity", "patriotism", "progress", "social justice" and "security". The listed values receive a variable linguistic expression in the texts of each period. It is shown that the evolution of the value component in the presidential campaign discourse manifests itself in the change of actors within the opposition "us - them", in variation of their linguistic representations, in modification of value dominants of discourse and in transformation of language means conveying evaluative meaning. The main set of value orientations of the discourse remains relatively constant, the changes are revealed in the model of conceptualization of the values and their influencing potential in the election communication.
\end{abstract}

Key words: discourse, election discourse, axiological characteristics of discourse, key words, corpus linguistics, value.

Citation. Kononova I.V., Melnichuk T.A. Dynamics of Values in American Election Discourse. Vestnik Volgogradskogo gosudarstvennogo universiteta. Seriya 2. Yazykoznanie [Science Journal of Volgograd State University. Linguistics], 2021, vol. 20, no. 4, pp. 113-125. (in Russian). DOI: https://doi.org/10.15688/jvolsu2.2021.4.9

\section{АКСИОЛОГИЧЕСКАЯ СОСТАВЛЯЮЩАЯ АМЕРИКАНСКОГО ПРЕДВЫБОРНОГО ДИСКУРСА В ДИНАМИЧЕСКОМ АСПЕКТЕ}

Инна Владимировна Кононова

Санкт-Петербургский государственный экономический университет, г. Санкт-Петербург, Россия

\section{Татьяна Александровна Мельничук}

Северо-Восточный федеральный университет им. М.К. Аммосова, г. Якутск, Россия

\footnotetext{
Аннотация. В статье представлены результаты применения корпусного подхода к анализу аксиологических характеристик политического дискурса. Привлечение метода идентификации ключевых слов корпуса позволило описать динамику ценностных доминант американского предвыборного дискурса в период с 1952 по 2016 год. Исследование проводилось на материале текстов видеороликов 17 президентских предвыборных кампаний. Тексты были разделены на три корпуса в соответствии с тремя историческими периодами: 1-й период - 1952-1972 гг.; 2-й период - 1976-2000 гг.; 3-й период - 2004-2016 годы. Установлено,
} 
что к инвариантным ценностям, объективируемым в предвыборных видеороликах на протяжении трех выделенных исторических периодов, относятся: «prosperity», «patriotism», «progress», «social justice», «security». Перечисленные ценности получают вариативное языковое выражение в текстах каждого из периодов. Показано, что эволюция ценностной составляющей предвыборного президентского дискурса проявляется в изменении состава акторов полюсов оппозиции «свои - чужие» и способов их языковой репрезентации, в модификации ценностных доминант текстов, а также в трансформации языковых средств выражения оценочных смыслов. Основной набор ценностных ориентиров дискурса остается относительно постоянным, изменяется модель концептуализации ценностей в сознании носителей культуры и их воздействующий потенциал в предвыборной коммуникации.

Ключевые слова: дискурс, предвыборный дискурс, аксиологические характеристики дискурса, ключевые слова, корпусная лингвистика, ценность.

Цитирование. Кононова И. В., Мельничук Т. А. Аксиологическая составляющая американского предвыборного дискурса в динамическом аспекте // Вестник Волгоградского государственного университета. Серия 2, Языкознание. - 2021. - Т. 20, № 4. - C. 113-125. - DOI: https://doi.org/10.15688/jvolsu2.2021.4.9

\section{Введение}

Исследование дискурса в аксиологическом аспекте представляет собой одно из наиболее активно развивающихся направлений современной лингвистики. В дискурсе как языковом проявлении социальных практик ценности генерируются и трансформируются во временной перспективе. Будучи интегральной частью дискурса, ценности фиксируют определенную модель мира, способствующую реализации целей определенных социальных институтов. Изучение ценностей в лингвистическом аспекте предполагает установление способов их фиксации в языковом сознании и коммуникативной практике.

Вопрос о выработке системного подхода к анализу ценностей с использованием конкретного инвентаря лингвистических инструментов не теряет актуальности, несмотря на солидную историю разработки данной проблемы. Ценности изучались на основе метода семантического дифференциала Ч. Осгуда, позволяющего провести количественное и качественное индексирование субъективных значений при помощи особых биполярных шкал [Воейкова, 2009]. Проблема описания ценностного содержания больших текстовых массивов решалась при помощи метода контент-анализа, предполагающего фиксацию определенных элементов содержания текстов с последующей количественной обработкой полученных данных [Broom, Reece, 1995]. В последнее время ценности исследуются с использованием корпусных методов, которые обеспечивают возможность выдвижения принципиально новых гипотез и выявления новых измерений в использовании языковых единиц на большом языковом / текстовом материале. На основе корпусной методологии рассматривались аксиологические характеристики новостного дискурса [Partington, 2010], рекламы [Кочетова, Кононова, 2019], PR-текстов [Кочетова, Попов, 2019].

В рамках типологического подхода к аксиологическим основаниям дискурса выявляются типы ценностей, на которые ориентирован дискурс, и модели поведения, которые он задает [Бобырева, 2007; Карасик, 2015; Кочетова, 2013б; Молодыченко, 2015; Шейгал, $2000 ;$ и др.]. С позиций исторического подхода к аксиологическим характеристикам дискурса относятся динамические процессы в дискурсивной ценностной картине мира, а также исторические изменения в способах ее языкового выражения. Совмещение типологического и диахронического подходов позволяет обнаружить ценности, функционирующие только на конкретном историческом этапе развития дискурса, и ценности, свойственные дискурсу константно. Так, проводя историческое исследование аксиологических оснований религиозного дискурса, Е.В. Бобырева выделяет конкретноисторические и абстрактно-универсальные ценности [Бобырева, 2007]. Л.А. Кочетова, рассматривая аксиологические характеристики англоязычного рекламного дискурса, приходит к заключению, что «специфика ценностной картины мира, зафиксированной в том или ином типе дискурса, определяется конкретным историческим периодом, соотносится с ведущими функциями дискурса и обладает инвари- 
антной и вариативной частью» [Кочетова, 2013a, c. 324].

Изучение ценностей с позиций лингвокультурологии состоит в выделении концептов, которые рассматриваются «как кванты переживаемого знания о том, что понимается как ценность» [Карасик, 2019, с. 23]. В дискурсивных концептуальных исследованиях ценность конструируется в тексте как «квант знания». По мере развертывания дискурса содержание определенной ценности / ценностей прирастает новыми смыслами. В тексте ценности находят выражение также в оценочных суждениях. С этой точки зрения понятие «ценность» тесно связано с понятием «оценка», то есть выражением своей позиции в отношении значимого для участников коммуникации явления действительности по признаку «хорошо / плохо».

Целью настоящего исследования является корпусное описание динамики ценностных характеристик американского предвыборного дискурса.

Аксиологический аспект политической коммуникации получил освещение в отечественной и зарубежной лингвистике [Гайкова, 2003; Дотдаева, 2013; Курушкин, 2017; Марьянчик, 2013; Шейгал, 2000; Sowinska, 2013]. Аксиологичность предвыборного дискурса представляет собой результат двустороннего процесса, где кандидат пытается повлиять на потенциального избирателя, с одной стороны, опираясь на ценности адресата, a с другой - транслируя определенные ценностные установки в своем сообщении [Мартынова, 2010]. Таким образом, ценности релевантны при конструировании политического дискурса, одновременно репрезентируя и формируя реальность.

Видам ценностей и способам их репрезентации в тексте посвящено немало исследований. Тён ван Дейк отмечал, что для политических текстов особое значение имеют социальные ценности: свобода, демократия, равноправие, поскольку именно эти ценности формируют отношение индивида и общества к социально-политическим проблемам [Dijk, 1998]. Такие ценности могут по-разному интерпретироваться в зависимости от идеологической самоидентификации индивида или группы. Большой вклад в исследование связи между идеологией и ценностями внес Норман Фэрклаф. В его работе «Язык и власть» с позиций критического анализа идеологизированного дискурса подробно рассматриваются эмпирические (experiential), связанные с отношениями внутри социума (relational) и экспрессивные (expressive) ценности [Fairclough, 2001]. Весьма детальная классификация политических, социальных и экономических ценностей и антиценностей предлагается в работе Ф.И. Дотдаевой, посвященной анализу аксиологем в выступлениях президентов США [Дотдаева, 2013].

По мнению большинства исследователей аксиологических характеристик политического дискурса, его базовыми ценностными координатами являются полюса оппозиции «свои - чужие» (см., например: [Марьянчик, 2013; Молодыченко 2015; Шейгал, 2000]). Данные полюса становятся центрами аттракции, вокруг которых аккумулируются свойственные политическому дискурсу ценностные оппозиции.

Исследователи американской политической культуры полагают, что ей присуще идеологическое противостояние сторонников республиканской и демократической партий, которое рассматривается в русле истории, политологии, социологии и теории дискурса (см., например: [Goren, 2005; Solomon, 2015; Spruill, 2017]). При этом важно учитывать, что подобная поляризация, довольно ярко выраженная в дискурсах либеральных и консервативных политических элит, слабо проявляется в индивидуальном сознании американцев [Hunter, Wolfe, 2006]. Многие авторы считают правомерным выделять общие ценности американской культуры, истоки которых можно найти в протестантской этике, идеалах Просвещения, покорении фронтира [D'Andrade, 2008; Peacock, 1995].

\section{Материал и методы}

В основе настоящего исследования лежит корпусный метод идентификации ключевых слов, который позволяет выявить доминирующие смысловые и ценностные характеристики дискурса. Сопоставительный анализ значимости слов в текстах основан на концепции «ключевого слова», которое определяет- 
ся как словоформа, имеющая более высокую частотность в анализируемом корпусе по сравнению с референтными корпусами [Taylor, Marchi, 2018]. Различаются типы ключевых слов в зависимости от того, выполняют ли они в первую очередь семантическую или стилистическую функцию, то есть отражают ли они содержание текста или характеристики стиля [Scott, Tribble, 2006]. С точки зрения репрезентации ценностных смыслов интерес представляют ключевые слова первого типа, поскольку именно они демонстрируют содержательные особенности дискурса и дают возможность установить семантические тенденции в его динамике.

В корпусной лингвистике ключевые слова определяются с помощью квантитативных статистических методов, позволяющих избежать субъективности в оценке степени значимости того или иного слова. Тем не менее очевидно, что простого выявления ключевых слов недостаточно для анализа текста, поскольку их роль и функционирование непосредственно зависят от контекста. Последующий квалитативный контекстный анализ выделенных ключевых слов необходим для более полной интерпретации полученных данных и описания дискурсивных характеристик текста.

Корпусный анализ текстов с целью идентификации значимых ключевых слов осуществлялся нами с использованием корпусменеджера AntConc [Anthony, 2019]. Статистическая значимость слова вычислялась с помощью формулы, устанавливающей специальный коэффициент Keyness $(K)$ для каждой словоформы в тексте с учетом частотности данной словоформы и общего количества словоупотреблений в исследуемом и референтном корпусах. Для определения пороговой величины статистической значимости ключевого слова используются $\mathrm{p}$-значение ( $p=$ probability value) и показатель логарифмического сходства $(\mathrm{LL}=\log$-likelihood) со значениями $p \leq 0.01, \mathrm{LL} \geq 6.63$. Таким образом, в исследуемом корпусе выделяются ключевые лексемы, демонстрирующие значимую разницу в частотности употребления по сравнению с референтным корпусом.

Систематизация репрезентируемых в текстах корпусов ценностей проводилась на основе семантической категоризации ключе- вых слов с учетом их регулярной сочетаемости и системных отношений в словарном составе английского языка. Например, глагол fail интерпретируется как репрезентант концепта «regress» в силу его регулярной сочетаемости со словами, обладающими семантическим признаком 'развитие, движение', например: fail to move ahead, fail to develop и пр.

Материалом для анализа послужили тексты видеороликов 17 американских президентских предвыборных кампаний с 1952 по 2016 год. Общее количество текстов составило 423 единицы. Тексты были разделены на три корпуса, соответствующие трем историческим периодам: 1-й период - 1952-1972 гг. (объем - 22777 слов); 2-й период - 19762000 гг. (объем - 19380 слов); 3-й период 2004-2016 гг. (объем - 18809 слов). В данном исследовании референтный корпус для текстов первого периода включает тексты второго и третьего периодов, для текстов второго периода - тексты первого и третьего периодов, для текстов третьего периода - тексты первого и второго периодов.

Выбранная периодизации обусловлена общностью внешне- и внутриполитических приоритетов США в рамках каждого временного отрезка. Так, в 1952-1972 гг. наиболее значимыми были темы, связанные с разделением мира на социалистический и капиталистический лагеря, холодной войной, борьбой за гражданские права афроамериканцев. Период с 1976 по 2000 г. характеризуется большим вниманием к проблемам внутренней политики: безработице, росту преступности, наркоторговле и пр. Событием, оказавшим огромное влияние на США периода 2004-2016 гг., является теракт 11 сентября 2001 г., последствиями которого стали такие политические приоритеты, как борьба с террористической угрозой, усиление национальной безопасности, борьба за соблюдение гражданских свобод и т. д.

\section{Результаты и обсуждение}

В соответствии с целью настоящего исследования в каждом из трех корпусов текстов были выявлены ключевые лексемы, демонстрирующие необычно высокую частотность по сравнению с референтным корпусом. Анализ 
И.В. Кононова, Т.А. Мельничук. Аксиологическая составляющая американского предвыборного дискурса

показал, что в каждом корпусе некоторую долю таких лексем составляют служебные слова, имена политических деятелей и слова, использующиеся в лозунге того или иного кандидата и показывающие высокую меру ключевой значимости за счет повторения лозунга в каждом ролике. Такие лексемы выходят за рамки ис- следования, поскольку не отражают аксиологической составляющей предвыборного дискурса. В итоговую таблицу (см. таблицу) вошли лексемы с частотностью не менее 4 (подробнее о частотности лексем в корпусном анализе см.: [Bowker, Pearson, 2002]), показавшие меру значимости ключевого слова 7 и выше.

\section{Ключевые слова трех подкорпусов текстов жанра президентского предвыборного ви- деоролика}

Key words extracted from the three subcorpora comprising texts of the presidential election commercials genre

\begin{tabular}{|c|c|c|c|c|c|}
\hline \multicolumn{2}{|c|}{ 1-й период } & \multicolumn{2}{|c|}{ 2-й период } & \multicolumn{2}{|c|}{ 3-й период } \\
\hline $\begin{array}{c}\text { Ключевые } \\
\text { слова }\end{array}$ & Keyness & $\begin{array}{c}\text { Ключевые } \\
\text { слова }\end{array}$ & Keyness & $\begin{array}{c}\text { Ключевые } \\
\text { слова }\end{array}$ & Keyness \\
\hline man & 51.46 & welfare & 46.96 & Iraq & 82.36 \\
\hline all & 30.59 & $\operatorname{tax}$ & 35.76 & jobs & 42.18 \\
\hline communism & 27.57 & harbor & 34.39 & she & 41.16 \\
\hline now & 25.23 & cut & 33.76 & supporters & 25.88 \\
\hline must & 21.74 & taxes & 27.64 & economy & 24.35 \\
\hline fail & 21.66 & drug & 27.26 & maverick & 23.52 \\
\hline states & 20.94 & control & 26.60 & we & 22.53 \\
\hline convention & 19.69 & state & 23.11 & breaks & 21.92 \\
\hline peace & 18.22 & hundred & 23.10 & troops & 21.28 \\
\hline general & 17.74 & thousand & 23.10 & coal & 21.17 \\
\hline confused & 15.75 & penalty & 22.93 & middle & 21.04 \\
\hline farmer & 15.75 & inflation & 22.35 & terrorists & 19.73 \\
\hline older & 15.75 & agents & 20.63 & energy & 18.22 \\
\hline society & 15.75 & surplus & 19.10 & oil & 17.86 \\
\hline individual & 15.71 & tuition & 19.10 & stronger & 17.35 \\
\hline united & 15.54 & tough & 17.56 & fundamentals & 16.47 \\
\hline think & 14.34 & increase & 17.45 & super & 16.47 \\
\hline communists & 13.79 & seniors & 16.99 & class & 16.33 \\
\hline farm & 13.79 & deficit & 16.09 & her & 14.71 \\
\hline problems & 13.73 & credit & 16.05 & companies & 14.54 \\
\hline rights & 12.97 & furloughs & 16.05 & commercial & 14.11 \\
\hline civil & 12.16 & protecting & 16.05 & donors & 14.11 \\
\hline miles & 12.16 & weekend & 16.05 & liberals & 14.11 \\
\hline way & 12.03 & work & 16.03 & hero & 13.28 \\
\hline address & 11.82 & rates & 15.59 & lost & 12.99 \\
\hline article & 11.82 & dream & 15.49 & China & 12.92 \\
\hline communist & 11.82 & tried & 14.79 & guy & 12.21 \\
\hline draft & 11.82 & plan & 14.61 & betrayed & 11.76 \\
\hline example & 11.82 & clean & 14.31 & celebrity & 11.76 \\
\hline influence & 11.82 & most & 14.08 & heroes & 11.76 \\
\hline well & 11.79 & discipline & 13.75 & miners & 11.76 \\
\hline thinking & 11.73 & medicare & 13.75 & offshore & 11.76 \\
\hline senator & 11.61 & murderers & 13.75 & outsourcing & 11.76 \\
\hline ever & 11.54 & reaganomics & 13.75 & plant & 11.76 \\
\hline young & 10.67 & record & 13.09 & terrorist & 11.76 \\
\hline come & 10.35 & weapons & 12.86 & turning & 11.43 \\
\hline much & 10.35 & water & 12.83 & served & 11.36 \\
\hline $\mathrm{I}$ & 10.31 & opposed & 12.42 & low & 11.31 \\
\hline afraid & 9.85 & best & 11.92 & worse & 10.54 \\
\hline amendment & 9.85 & balanced & 11.73 & billions & 10.29 \\
\hline committee & 9.85 & doubled & 11.73 & someone & 10.29 \\
\hline
\end{tabular}


Окончание таблищуы

End of Table

\begin{tabular}{|c|c|c|c|c|c|}
\hline \multicolumn{2}{|c|}{ 1-й период } & \multicolumn{2}{|c|}{ 2-й период } & \multicolumn{2}{|c|}{ 3-й период } \\
\hline $\begin{array}{c}\text { Ключевые } \\
\text { слова }\end{array}$ & Keyness & $\begin{array}{c}\text { Ключевые } \\
\text { слова }\end{array}$ & Keyness & $\begin{array}{c}\text { Ключевые } \\
\text { слова }\end{array}$ & Keyness \\
\hline develop & 9.85 & desperate & 11.46 & terror & 10.29 \\
\hline doctrine & 9.85 & duty & 11.46 & overseas & 9.89 \\
\hline endurance & 9.85 & era & 11.46 & star & 9.89 \\
\hline floor & 9.85 & limits & 11.46 & my & 9.86 \\
\hline gentlemen & 9.85 & oval & 11.46 & plan & 9.60 \\
\hline interested & 9.85 & passes & 11.46 & abortions & 9.41 \\
\hline ladies & 9.85 & toxic & 11.46 & corrupt & 9.41 \\
\hline prejudice & 9.85 & military & 11.36 & depression & 9.41 \\
\hline Russian & 9.85 & raised & 10.78 & dishonest & 9.41 \\
\hline going & 9.83 & space & 10.78 & dishonorable & 9.41 \\
\hline white & 9.41 & standards & 10.78 & fewer & 9.41 \\
\hline he & 9.40 & raise & 10.72 & funding & 9.41 \\
\hline citizens & 9.38 & spending & 10.57 & movement & 9.41 \\
\hline constitution & 8.69 & dollars & 9.98 & pioneers & 9.41 \\
\hline happy & 8.69 & money & 9.96 & sacrifices & 9.41 \\
\hline natural & 8.69 & proliferation & 9.44 & struggling & 9.41 \\
\hline poverty & 8.69 & deficits & 9.43 & torture & 9.41 \\
\hline order & 8.45 & reform & 9.37 & veterans & 9.41 \\
\hline war & 8.22 & personal & 9.23 & wealth & 9.41 \\
\hline violence & 8.16 & college & 9.18 & captured & 9.11 \\
\hline conquer & 7.88 & schools & 9.18 & challenges & 9.11 \\
\hline constitutional & 7.88 & affordable & 9.17 & common & 9.11 \\
\hline peaceful & 7.88 & arms & 9.17 & intelligence & 9.11 \\
\hline poorer & 7.88 & furlough & 9.17 & killing & 9.11 \\
\hline victory & 7.88 & incentives & 9.17 & steel & 9.11 \\
\hline willing & 7.88 & missile & 9.17 & wealthy & 9.11 \\
\hline speech & 7.54 & budgets & 8.45 & September & 8.623 \\
\hline greatest & 7.05 & largest & 8.45 & deserve & 8.41 \\
\hline \multirow[t]{2}{*}{ Korea } & \multirow[t]{2}{*}{7.05} & \multirow[t]{2}{*}{ million } & \multirow[t]{2}{*}{7.70} & crisis & 7.16 \\
\hline & & & & lying & 7.09 \\
\hline
\end{tabular}

Текстовая семантика в исследуемых корпусах аккумулируется вокруг двух полюсов ценностного содержания: ценностям полюса «своих» противопоставляется отсутствие моральных ценностей и идеалов, свойственное полюсу «чужих». Анализ ключевых слов корпуса показал, что динамические процессы ценностной составляющей текстов проявляются в изменении состава акторов полюсов «свои - чужие», способах их языковой репрезентации, трансформации набора основных ценностей, а также модификации способов выражения оценочных смыслов.

Главными акторами, формирующими оппозицию «свои - чужие» в американском предвыборном политическом дискурсе, выступают кандидат и оппонент. Константная часть состава «своих» на протяжении трех исследуемых периодов репрезентирована сле- дующими акторами: кандидат, его сторонники, выдвинувшая его партия и американский народ; полюс «чужие» инвариантно представлен оппонентом и его сторонниками. Однако в текстах каждого из периодов анализ ключевых слов позволил определить вариативную часть представителей «своих» и «чужих», а также особенности способов их языковой репрезентации.

Так, в текстах первого периода ключевыми словами являются местоимения $I(K=10.31)$ и $h e(K=9.40)$, отражающие противостояние «кандидат - оппонент». Употребление местоимений $I$ и he подчеркивает роль кандидата и оппонента как индивидуальных акторов. Ср.: To do that I've got to go out and see you in person, and that's what I've been doing (XX); I ask you to help me make the American dream come true... (XVIII); I'm voting for Ike because 
I feel that he is a God-fearing man (VIII). В текстах третьего периода ключевым словом становится инклюзивное местоимение $w e$ $(K=22.53)$, которое используется в предвыборном президентском дискурсе с целью демонстрации солидаризации кандидата с его электоратом на основе общих идеалов и ценностей. Ср.: We depend more than ever on our values - family, faith, the freedom we celebrate (IV).

Акторами в поле «своих» и «чужих» в исследуемых текстах могут быть как одушевленные, так и неодушевленные агенты, выраженные, как правило, существительными с собирательным значением (companies, corporations), а также абстрактные понятия (communism, terrorism, poverty).

Ключевыми словами, репрезентирующими полюс «чужих» в текстах первого периода являются: communism (27.57), communists (13.79), Russian (9.85); в качестве вариативно характеризующей этот период номинации акторов «своих» можно выделить словосочетание [American] citizens (9.38). Одной из основных идеологических оппозиций, свойственных первому периоду, можно назвать противостояние демократических ценностей и коммунистической идеологии; антисоветские настроения были очень сильны в американском обществе в обстановке холодной войны. Ср.: Equal rights for all our citizens. Why must we vigorously defend them? First, because it is right and just, and second, because we cannot compete successfully with communism, if we fail to utilize completely the minds and energies of all of our citizens (XVI).

В корпусе текстов второго периода основными темами предвыборных президентских видеороликов становятся борьба с экономическим упадком и безработицей, а также борьба с преступностью. Ключевым словом в текстах этого периода является лексема murderers (13.75). В предвыборных роликах в поддержку Джорджа Буша активно обсуждается введение смертной казни за особо тяжкие преступления, осуждается либеральное отношение к осужденным за убийство преступникам. Ср.: Bush supports the death penalty for first degree murderers (II); ...he [Dukakis] allowed first degree murderers to have weekend passes (II).

В третьем периоде основной конфликт между «своими» и «чужими» связан с пробле- мой борьбы с терроризмом. Высокую меру Keyness имеют лексемы terrorists (19.73), terror (10.29), Iraq (82.36), номинирующие полюс «чужих» (врагов); полюс «своих» репрезентирован в данном корпусе помимо инвариантного набора единиц (I, we, American people, Americans и пр.) словами veterans (9.41), hero (13.28), heroes (11.76), troops (21.28). Cp.: As our troops defend America in the War on Terror they must have what it takes to win (VI); Our soldiers fighting in Iraq are heroes (XII); And then we will be able to tell the terrorists: "You will lose, and we will win" (XIII).

Значимым в текстах третьего периода является также противостояние между рядовыми американцами и крупными компаниями относительно создания рабочих мест в США и отказа от переноса производства с целью его удешевления в страны третьего мира. В следующем контексте Барак Обама объединяет себя с рядовыми американцами, помещая на противоположный полюс корпорации, игнорирующие национальные интересы, а также своих оппонентов, которые не разделяют его интересы: I'll end the tax breaks for companies that ship our jobs overseas, and give them to companies that create jobs here in America (XIX). Лексемы jobs (42.18) и companies (14.54) имеют высокую меру Keyness в корпусе третьего периода.

В текстовом представлении «чужие» не имеют моральных принципов и идеалов, в то время как для семантического наполнения полюса «своих» используется лексика, репрезентирующая традиционные морально-этические ценности американской культуры (patriotism, freedom, democracy, justice, civil rights и пр.), а также оценочная лексика положительной семантики.

Анализ ключевых слов трех подкорпусов текстов позволил выделить доминантные для каждого из периодов ценности. К ключевым словам корпуса первого периода относятся лексемы, прямо или косвенно репрезентирующие следующие ценности / антиценности американской культуры: «реасе» (peace, peaceful), «War» (communism, communists, war, Russian, Korea), «patriotism» (all, united, states, citizens), «poverty» (poverty, poorer), «justice» (rights, civil), «injustice» (prejudice), «security» (order), «insecurity» (violence), «regress» (fail). В кор- 
пусе текстов второго периода ключевые слова актуализируют такие ценностные концепты, как «progress» (surplus, increase, balanced, affordable, [American] dream), «stagnation / regress» (inflation, deficit, deficits, spending), «right to work» (work, welfare), «insecurity» (drug, furloughs, furlough, murderers, [death] penalty), "war» (military, weapons, arms, missile), «peace» (proliferation), «ecology» (clean, water). В текстах третьего периода ключевую значимость получают лексемы-репрезентанты следующих ценностей и антиценностей: «prosperity» (wealth, wealthy); «patriotism» (veterans, hero, heroes, troops, sacrifices, common); «progress» (stronger, plan); «insecurity» (terror, terrorists, terrorist, Iraq, Middle [East], torture, killing, crisis); «poverty» (struggling); «honor /dishonor» (betrayed, dishonest, dishonorable); «stagnation / regress» (worse, low, lost) и пр.

Сравнительный анализ позволил заключить, что основной набор ценностных ориентиров, свойственный исследуемому типу дискурса, остается константным на протяжении всего существования жанра американского предвыборного дискурса. К ценностям, которые являются актуальными для каждого из выделенных периодов, относятся: «prosperity», «patriotism», «progress», «social justice», «security»». Ценность «реасе» актуальна для двух периодов, ценности «еcology» и «honor» - для одного. Несмотря на то что основной набор ценностных ориентиров остается относительно константным, в силу культурноисторических и социальных причин изменяется осмысление концептов носителями культуры и их воздействующий потенциал в предвыборной коммуникации.

Рассмотрим для примера динамику двух ценностей, представленных в исследуемом дискурсе, - «реасе» и «security».

В текстах первого периода ценность «реасе» связывается в первую очередь с холодной войной и «коммунистической угрозой» (world peace is threatened by Communism (XI); the growing menace of Communism (XVII)), а также с угрозой ядерной войны (If he means that people don't want to fight a nuclear war, he's right (X)). В текстах второго периода ценность «реасе» конструируется в аспекте противостояния гонке вооружений и угрозе ядерной войны, однако не связывается с коммунистической идеологией (he makes a very disturbing comment that nonproliferation or the control of the spread of nuclear weapons is none of our business (VII); the arms race will rage out of control (XV)).

Ценностная оппозиция «security / insecurity» остается актуальной на протяжении трех рассматриваемых периодов. В текстах первого и второго подкорпусов она осмысливается в первую очередь как личностная неприкосновенность граждан. В текстах первого периода безопасность ассоциируется с борьбой с уличной преступностью и межрасовой агрессией, восстановлением и поддержанием правопорядка (The leadership of this nation has a clear and immediate challenge... to restore proper respect for law and order in this land (IX)). В текстах второго периода получают значимость аспекты безопасности, связанные с наркоторговлей и нежелательной гуманизацией пенитенциарной системы (Michael Dukakis vetoed mandatory sentences for drug dealers, he vetoed the death penalty (I); His revolving door prison policy gave weekend furloughs to first degree murderers (I)). В текстах третьего периода интерпретация данной ценности претерпевает большие изменения: в фокусе - вопросы национальной безопасности, угроза терроризма и война в Ираке. Ср.: Donald Trump's America is secure. Terrorists and dangerous criminals kept out (XXI). Очевидно, что смещение акцентов с внутренней угрозы на внешнюю связано с изменением политических приоритетов: если в 1970-е гг. Ричард Никсон объявил войну наркотикам (war on drugs), то в 2000-е гг. Джордж Буш начал войну с терроризмом (war on terror).

Важным аспектом аксиологического исследования дискурса является определение способов выражения оценочной позиции автора по отношению к ценностному содержанию текста. Для проекции в текстовые структуры позиции автора и стоящей за ним группы «своих» используются языковые средства оценки. Результаты корпусного анализа свидетельствуют о роли, которую оценочная лексика играет в моделировании ценностей в текстах. Обращает на себя внимание рост количества ключевых слов с отрицательной морально- 
этической оценкой в текстах третьего периода. Прилагательные corrupt (9.41), dishonest (9.41), dishonorable (9.41), предикаты betrayed (11.76), lying (7.09) выражают осуждение и конструируют «антиценностное» поле, в котором функционируют акторы полюса «чужих». Cp.: Who is Barack Obama? He says our troops in Afghanistan are just air-raiding villages and killing civilians... How dishonorable (XIV); He [George W. Bush] betrayed us in the past. How could we be loyal to him now (V).

Значительную роль в формировании ценностной модели предвыборного дискурса играют также специальные знаки, служащие активации механизмов интертекстуальности. К ним относятся слова, номинирующие национально-прецедентные феномены. Например, в текстах второго периода высокую меру Keyness демонстрирует лексема dream (15.49), репрезентирующая прецедентное для американской культуры понятие «American dream». В корпусе текстов третьего периода ключевым словом является лексема September (8.623), отсылающая к теракту 11 сентября 2001 года. Cp: My wife Wendy was murdered by terrorists on September $11^{\text {th }}$. How do you think we felt when we heard the Senate report that said there was no link between Iraq and 9/11? (III).

\section{Выводы}

В результате анализа репрезентаций дискурса корпусными методами описана динамика аксиологических характеристик американского предвыборного президентского видеоролика. Привлечение метода идентификации ключевых слов позволило выявить основные ценности, используемые в американском предвыборном дискурсе с целью побуждения адресата к принятию желаемого для адресанта посткоммуникативного решения.

Анализ ключевых слов корпуса показал, что эволюция ценностной составляющей текстов предвыборных президентских видеороликов обнаруживается в изменении состава акторов полюсов оппозиции «свои - чужие», способах их языковой репрезентации, трансформации набора основных ценностей / антиценностей, которые им приписываются, а так- же в модификации способов выражения оценочных смыслов текста.

Привлечение метода ключевых слов корпуса позволило сделать верифицированные выводы об инвариантных и вариативных характеристиках аксиологической составляющей американского президентского предвыборного дискурса. Показано, что инвариантными ценностями, репрезентируемыми в текстах предвыборных видеороликов на протяжении трех выделенных исторических периодов, являются: «prosperity», «patriotism», «progress», «social justice», «security». Перечисленные ценности получают вариативную языковую репрезентацию в текстах каждого из периодов, уточняются при помощи квантификаторов, предикатов и атрибутов оценочной семантики, оказывающих воздействие на адресата. Несмотря на то что основной набор ценностных ориентиров дискурса остается относительно постоянным, изменяется модель их концептуализации в сознании носителей культуры и воздействующий потенциал в предвыборной коммуникации.

\section{СПИСОК ЛИТЕРАТУРЫ}

Бобырева Е. В., 2007. Религиозный дискурс: ценности, жанры, стратегии (на материале православного вероучения) : автореф. дис. ... д-ра филол. наук. Волгоград. $43 \mathrm{c}$.

Воейкова А. А., 2009. Ценностные концепты русских и американских рекламных текстов и их анализ методом семантического дифференциала // Вестник Челябинского государственного университета. № 35 (173), вып. 37. C. $27-30$.

Гайкова О. В., 2003. Предвыборный дискурс как жанр политической коммуникации : дис. ... канд. филол. наук. Волгоград. 210 c.

Дотдаева Ф. И., 2013. Языковые средства ценностного воздействия в американском президентском дискурсе : автореф. дис. ... канд. филол. наук. Пятигорск. $23 \mathrm{c}$.

Карасик В. И., 2015. Языковая спираль: ценности, знаки, мотивы. Волгоград : Парадигма. 432 с.

Карасик В. И., 2019. Ценности как культурно значимые ориентиры поведения // Гуманитарные технологии в современном мире : сб. материалов VII Междунар. науч.-практ. конф. (Калининград, 30 мая 2019 г.). Калининград : Зап. фил. Рос. акад. нар. хоз-ва и гос. службы при Президенте Рос. Федерации. С. 22-25. 
Кочетова Л. А., 2013а. Английский рекламный дискурс в динамическом аспекте : дис. ... д-ра филол. наук. Волгоград. 438 с.

Кочетова Л. А., 2013б. Динамика аксиологических характеристик рекламного дискурса // Гуманитарные и социально-экономические науки. № 2 (69). С. 61-64.

Кочетова Л. А., Кононова И. В., 2019. Когнитивно-корпусный подход к анализу конструирования ценностных смыслов в рекламном дискурсе // Вопросы когнитивной лингвистики. № 2. С. 65-74.

Кочетова Л. А., Попов В. В., 2019. Исследование аксиологических доминант в жанре прессрелиза на основе методов автоматического извлечения ключевых слов корпуса текстов // Научный диалог. № 6. С. 32-49.

Курушкин С. В., 2017. Ценностно-политический дискурс сетевых сообществ: на материалах Интернет-СМИ России : дис. ... канд. полит. наук. СПб. $166 \mathrm{c.}$

Мартынова Ю. А., 2010. Лингвопрагматический аспект формирования системы ценностей в политическом дискурсе // Известия Саратовского университета. Серия «Социология. Политология». Т. 10, вып. 1. С. 114-116.

Марьянчик В. А., 2013. Аксиологичность и оценочность медиа-политического текста : монография. M. : URSS. 266 c.

Молодыченко Е. Н., 2015. Аксиологические основания политического дискурса // Научно-технические ведомости Санкт-Петербургского государственного политехнического университета. Общество. Коммуникация. Образование. № 1 (215). С. 9-17.

Шейгал Е. И., 2000. Семиотика политического дискурса : дис. ... д-ра филол. наук. Волгоград. 431 с.

Anthony L., 2019. AntConc (Version 3.5.8) : [Computer Software]. Tokyo : Waseda University. URL: http://www.laurenceanthony.net/ (date of access: 04.12.2019).

Bowker L., Pearson J., 2002. Working with Specialized Language: A Practical Guide to Using Corpora. L. ; N. Y. : Routledge. 242 p.

Broom L., Reece S., 1995. Political and Racial Interest: A Study in Content Analysis // The Public Opinion Quarterly. Vol. 19, № 1. P. 5-19.

D'Andrade R., 2008. A Study of Personal and Cultural Values: American, Japanese, and Vietnamese. N. Y. : Palgrave Macmillan. 173 p.

Dijk T. A. van, 1998. Ideology: A Multidisciplinary Approach. L. : Sage. 365 p.

Fairclough N., 2001. Language and Power. L. : Routledge. 226 p.

Goren P., 2005. Party Identification and Core Political Values // American Journal of Political Science. Vol. 49, № 4. P. 881-896.
Hunter J. D., Wolfe A., 2006. Is There a Culture War?: A Dialogue on Values and American Public Life. Washington, DC : Brookings Institution Press. $118 \mathrm{p}$.

Partington A., 2010. Modern Diachronic CorpusAssisted Discourse Studies on UK Newspapers: An Overview of the Project // Corpora. Vol. 5, iss. 2. P. 83-108.

Peacock J. L., 1995. American Cultural Values: Disorders and Challenges // Diagnosing America: Anthropology and Public Engagement / ed. by S. Forman. Ann Arbor : University of Michigan Press. P. 23-50.

Scott M., Tribble C., 2006. Textual Patterns: Key Words and Corpus Analysis in Language Education. Amsterdam : John Benjamins Publishing. 214 p.

Solomon T., 2015. The Politics of Subjectivity in American Foreign Policy Discourses. Ann Arbor : University of Michigan Press. 264 p.

Sowinska A., 2013. A Critical Discourse Approach to the Analysis of Values in Political Discourse: The Example of Freedom in President Bush's State of the Union Addresses (2001-2008) // Discourse \& Society. Vol. 24, № 6. P. 792-809.

Spruill M. J., 2017. Divided We Stand: The Battle Over Women's Rights and Family Values That Polarized American Politics. N. Y. : Bloomsbury. $448 \mathrm{p}$.

Taylor C., Marchi A., 2018. Corpus Approaches to Discourse: A Critical Review. L. : Routledge. $314 \mathrm{p}$.

\section{ИСТОЧНИКИ}

I - Bush 1988. Revolving Door. URL: http://www. livingroomcandidate.org/commercials/1988/ revolving-door (date of access: 15.09.2020).

II - Bush 1988. Willie Horton. URL: http://www. livingroomcandidate.org/commercials/1988/ willie-horton (date of access: 15.09.2020).

III - Bush 2004. Ashley's Story. URL: http://www. livingroomcandidate.org/commercials/2004/ ashleys-story (date of access: 15.09.2020).

$I V-$ Bush 2004. Changing World. URL: http://www. livingroomcandidate.org/commercials/2004/ changing-world (date of access: 15.09.2020).

$V$ - Bush 2004. Sellout. URL: http://www. livingroomcandidate.org/commercials/2004/ sellout (date of access: 15.09.2020).

$V I$ - Bush 2004. Weapons. URL: http://www. livingroomcandidate.org/commercials/2004/ weapons-florida (date of access: 15.09.2020).

VII - Carter 1980. Flipflop. URL: http://www. livingroomcandidate.org/commercials/1980/ flipflop (date of access: 15.09.2020). 
VIII - Eisenhower 1956. Women Voters. URL: http:// www.livingroomcandidate.org/commercials/ 1956/women-voters (date of access: 15.09.2020).

IX - Goldwater 1964. Morality. URL: http://www. livingroomcandidate.org/commercials/1964/ morality (date of access: 15.09.2020).

$X$ - Johnson 1964. Confessions of a Republican. URL: $\mathrm{http}$ //www.livingroomcandidate.org/commercials/ 1964/confessions-of-a-republican (date of access: 15.09.2020).

$X I$ - Kennedy 1960. Mrs JFK. URL: http://www. livingroomcandidate.org/commercials/1960/mrsjfk (date of access: 15.09.2020).

$X I I$ - Kerry 2004. Heroes. URL: http://www. livingroomcandidate.org/commercials/2004/ heroes (date of access: 15.09.2020).

XIII - Kerry 2004. Strength. URL: http://www. livingroomcandidate.org/commercials/2004/ strength (date of access: 15.09.2020).

$X I V-$ McCain 2008. Dangerous. URL: http://www. livingroomcandidate.org/commercials/2008/ dangerous (date of access: 15.09.2020).

$X V$ - Mondale 1984. Orbiting. URL: http://www. livingroomcandidate.org/commercials/1984/ orbiting (date of access: 15.09.2020).

XVI - Nixon 1960. Civil Rights. URL: http://www. livingroomcandidate.org/commercials/1960/ civil-rights (date of access: 15.09.2020).

XVII - Nixon 1960. Freedom. URL: http://www. livingroomcandidate.org/commercials/1960/ nixons-experience\#/video/1960-r-freedom500.mp4 (date of access: 15.09.2020).

XVIII - Nixon 1968. Child's Face. URL: http://www. livingroomcandidate.org/commercials/1968/ childs-face (date of access: 15.09.2020).

XIX-Obama 2008. Defining Moment. URL: https:// www.youtube.com/watch?v=vJvkRFKGgGw (date of access: 10.08.2020).

$X X-$ Stevenson 1956. The Man from Libertyville: TV Campaigning. URL: http://www. livingroomcandidate.org/commercials/1956/ the-man-from-libertyville-tv-campaigning (date of access: 15.09.2020).

XXI - Trump 2016. Two Americas: Immigration. URL:

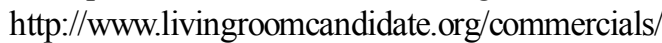
2016/two-americas-immigration (date of access: 15.09.2020).

\section{REFERENCES}

Bobyreva E.V., 2007. Religioznyi diskurs: tsennosti, zhanry, strategii (na materiale pravoslavnogo veroucheniya): avtoref. dis. ... d-ra filol. nauk [Religious Discourse: Values, Genres, Strategies (Case-Study of Orthodox Docrtine). Dr. philol. sci. abs. diss.]. Volgograd. $43 \mathrm{p}$.
Voeykova A.A., 2009. Tsennostnye kontsepty russkikh i amerikanskikh reklamnykh tekstov $i$ ikh analiz metodom semanticheskogo differentsiala [Axiological Concepts in Russian and American Advertisements and Semantic Differential Analysis Thereof]. Vestnik Chelyabinskogo gosudarstvennogo universiteta [Bulletin of Chelyabinsk State University], no. 35 (173), iss. 37, pp. 27-30.

Gaykova O.V., 2003. Predvybornyi diskurs kak zhanr politicheskoy kommunikatsii: dis. ... kand. filol. nauk [Election Discourse As a Genre of Political Communication. Cand. philol. sci. diss.]. Volgograd. $210 \mathrm{p}$.

Dotdaeva F.I., 2013. Yazykovye sredstva tsennostnogo vozdeystviya $v$ amerikanskom prezidentskom diskurse: avtoref. dis. ... kand. filol. nauk [Linguistic Means of Value-Based Manipulation in American Presidential Discourse. Cand. philol. sci. abs. diss.]. Pyatigorsk. 23 p.

Karasik V.I., 2015. Yazykovaya spiral': tsennosti, znaki, motivy [Language Spiral: Values, Signs, Motives]. Volgograd, Paradigma Publ. 432 p.

Karasik V.I., 2019. Tsennosti kak kul'turno znachimye orientiry povedeniya [Values As Culturally Significant Behavioural Guidelines]. Gumanitarnye tekhnologii $v$ sovremennom mire: $s b$. materialov VII Mezhdunar. nauch.-prakt. konf. (Kaliningrad, 30 maya 2019 g.) [Humane Technologies in the Modern World. Proceedings of the $7^{\text {th }}$ International Scientific and Practical Conference (Kaliningrad, May 30, 2019)]. Kaliningrad, Zapadnyi filial Rossiyskoy akademii narodnogo khozyaystva i gosudarstvennoy sluzhby pri Prezidente Rossiyskoy Federatsii, pp. 22-25.

Kochetova L.A., 2013a. Angliyskiy reklamnyy diskurs v dinamicheskom aspekte: dis. ... d-rafilol. nauk [English Advertising Discourse: Dynamic Aspect. Dr. philol. sci. diss.]. Volgograd. 438 p.

Kochetova L.A., 2013b. Dinamika aksiologicheskikh kharakteristik reklamnogo diskursa [Dynamics of Axiological Characteristics of an Advertisement Discourse]. Gumanitarnye $i$ sotsial'no-ekonomicheskie nauki [The Humanities and Social-Economic Sciences], no. 2 (69), pp. 61-64.

Kochetova L.A., Kononova I.V., 2019. Kognitivnokorpusnyi podkhod $\mathrm{k}$ analizu konstruirovaniya tsennostnykh smyslov $\mathrm{v}$ reklamnom diskurse [Cognitive Corpus Approach to Analysing Values in Advertising Discourse]. Voprosy kognitivnoy lingvistiki [Issues of Cognitive Linguistics], no. 2, pp. 65-74.

Kochetova L.A., Popov V.V., 2019. Issledovanie aksiologicheskikh dominant $\mathrm{v}$ zhanre press-reliza 
na osnove metodov avtomaticheskogo izvlecheniya klyuchevykh slov korpusa tekstov [Research of Axiological Dominants in Press Release Genre Based on Automatic Extraction of Keywords from Corpus]. Nauchnyi dialog, no. 6 , pp. 32-49.

Kurushkin S.V., 2017. Tsennostno-politicheskiy diskurs setevykh soobshchestv: na materialakh Internet-SMI Rossii: dis. ... kand. polit. nauk [Value-Based Political Discourse of Online Communities. Case Study of Russian Online Media. Cand. polit. sci. diss.]. Saint Petersburg. $166 \mathrm{p}$.

Martynova Yu.A., 2010. Lingvopragmaticheskiy aspekt formirovaniya sistemy tsennostey $\mathrm{v}$ politicheskom diskurse [Linguopragmatical Aspect of Value System Forming in Political Discourse]. Izvestiya Saratovskogo universiteta. Seriya "Sotsiologiya. Politologiya" [Izvestiya of Saratov University. Series "Sociology. Politology"], vol. 10, iss. 1, pp. 114-116.

Mar'yanchik V.A., 2013. Aksiologichnost' $i$ otsenochnost' media-politicheskogo teksta: monografiya [Axiological and Evaluative Aspects of Political Media Texts. Monograph]. Moscow, URSS Publ. 266 p.

Molodychenko E.N., 2015. Aksiologicheskie osnovaniya politicheskogo diskursa [Axiological Dimension of Political Discourse]. Nauchnotekhnicheskie vedomosti Sankt-Peterburgskogo gosudarstvennogo politekhnicheskogo universiteta. Obshchestvo. Kommunikatsiya. Obrazovanie [St. Petersburg State Polytechnical University Journal. Humanities and Social Sciences], no. 1 (215), pp. 9-17.

Sheygal E.I., 2000. Semiotika politicheskogo diskursa: dis. ... d-ra filol. nauk [Semiotics of Political Discourse. Dr. philol. sci. diss.]. Volgograd. 431 p.

Anthony L., 2019. AntConc (Version 3.5.8). Computer Software. Tokyo, Waseda University. URL: http:/ /www.laurenceanthony.net (accessed 4 December 2019).

Bowker L., Pearson J., 2002. Working with Specialized Language: A Practical Guide to Using Corpora. London, New York, Routledge. $242 \mathrm{p}$.

Broom L., Reece S., 1995. Political and Racial Interest: A Study in Content Analysis. The Public Opinion Quarterly, vol. 19, no. 1, pp. 5-19.

D'Andrade R., 2008. A Study of Personal and Cultural Values: American, Japanese, and Vietnamese. New York, Palgrave Macmillan. 173 p.

Dijk T.A. van, 1998. Ideology: A Multidisciplinary Approach. London, Sage. 365 p.

Fairclough N., 2001. Language and Power. London, Routledge. 226 p.
Goren P., 2005. Party Identification and Core Political Values. American Journal of Political Science, vol. 49, no. 4, pp. 881-896.

Hunter J.D., Wolfe A., 2006. Is There a Culture War?: A Dialogue on Values and American Public Life. Washington, DC, Brookings Institution Press. 118 p.

Partington A., 2010. Modern Diachronic CorpusAssisted Discourse Studies on UK Newspapers: An Overview of the Project. Corpora, vol. 5, iss. 2, pp. 83-108.

Peacock J.L., 1995. American Cultural Values: Disorders and Challenges. Forman S., ed. Diagnosing America: Anthropology and Public Engagement. Ann Arbor, University of Michigan Press, pp. 23-50.

Scott M., Tribble C., 2006. Textual Patterns: Key Words and Corpus Analysis in Language Education. Amsterdam, John Benjamins Publishing. 214 p.

Solomon T., 2015. The Politics of Subjectivity in American Foreign Policy Discourses. Ann Arbor, University of Michigan Press. 264 p.

Sowinska A., 2013. A Critical Discourse Approach to the Analysis of Values in Political Discourse: The Example of Freedom in President Bush's State of the Union Addresses (2001-2008). Discourse \& Society, vol. 24, no. 6, pp 792-809.

Spruill M.J., 2017. Divided We Stand: The Battle Over Women's Rights and Family Values that Polarized American Politics. New York, Bloomsbury. $448 \mathrm{p}$.

Taylor C., Marchi A., 2018. Corpus Approaches to Discourse: A Critical Review. London, Routledge. 314 p.

\section{SOURCES}

Bush 1988. Revolving Door. URL: http://www. livingroomcandidate.org/commercials/1988/ revolving-door (accessed 15 September 2020).

Bush 1988. Willie Horton. URL: http://www. livingroomcandidate.org/commercials/1988/ willie-horton (accessed 15 September 2020).

Bush 2004. Ashley's Story. URL: http://www. livingroomcandidate.org/commercials/2004/ ashleys-story (accessed 15 September 2020).

Bush 2004. Changing World. URL: http://www. livingroomcandidate.org/commercials/2004/ changing-world (accessed 15 September 2020).

Bush 2004. Sellout. URL: http://www. livingroomcandidate.org/commercials/2004/ sellout (accessed 15 September 2020).

Bush 2004. Weapons. URL: http://www. livingroomcandidate.org/commercials/2004/ weapons-florida (accessed 15 September 2020). 
Carter 1980. Flipflop. URL: http://www. livingroomcandidate.org/commercials/1980/ flipflop (accessed 15 September 2020).

Eisenhower 1956. Women Voters. URL: http://www. livingroomcandidate.org/commercials/1956/ women-voters (accessed 15 September 2020).

Goldwater 1964. Morality. URL: http://www. livingroomcandidate.org/commercials/1964/ morality (accessed 15 September 2020).

Johnson 1964. Confessions of a Republican. URL:

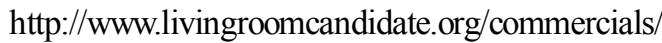
1964/confessions-of-a-republican (accessed 15 September 2020).

Kennedy 1960. Mrs JFK. URL: http://www. livingroomcandidate.org/commercials/1960/mrsjfk (accessed 15 September 2020).

Kerry 2004. Heroes. URL: http://www. livingroomcandidate.org/commercials/2004/ heroes (accessed 15 September 2020).

Kerry 2004. Strength. URL: http://www. livingroomcandidate.org/commercials/2004/ strength (accessed 15 September 2020).

McCain 2008. Dangerous. URL: http://www. livingroomcandidate.org/commercials/2008/ dangerous (accessed 15 September 2020).
Mondale 1984. Orbiting. URL: http://www. livingroomcandidate.org/commercials/1984/ orbiting (accessed 15 September 2020).

Nixon 1960. Civil Rights. URL: http://www. livingroomcandidate.org/commercials/1960/ civil-rights (accessed 15 September 2020).

Nixon 1960. Freedom. URL: http://www. livingroomcandidate.org/commercials/1960/ nixons-experience\#/video/1960-r-freedom500.mp4 (accessed 15 September 2020).

Nixon 1968. Child's Face. URL: http://www. livingroomcandidate.org/commercials/1968/ childs-face (accessed 15 September 2020).

Obama 2008. Defining Moment. URL: https://www. youtube.com/watch? v=vJvkRFKGgGw (accessed 15 September 2020).

Stevenson 1956. The Man from Libertyville: TV Campaigning. URL: http://www. livingroomcandidate. org/commercials/1956/theman-from-libertyville-tv-campaigning (accessed 10 August 2020).

Trump 2016. Two Americas: Immigration. URL: http:// www.livingroomcandidate.org/commercials/ 2016/two-americas-immigration (accessed 15 September 2020).

\section{Information About the Authors}

Inna V. Kononova, Doctor of Sciences (Philology), Professor, Department of English Philology and Translation, Saint Petersburg State University of Economics, Griboedov Channel Emb., 30-32, 191023 Saint Petersburg, Russia, inkon_71@mail.ru, https://orcid.org/0000-0003-4903-5856

Tatiana A. Melnichuk, Associate Professor, Department of English Philology, M.K. Ammosov North-Eastern Federal University, Belinskogo St, 58, 677000 Yakutsk, Russia, melnichuk.ta@gmail.com, https://orcid.org/0000-0002-8126-0925

\section{Информация об авторах}

Инна Владимировна Кононова, доктор филологических наук, профессор кафедры английской филологии и перевода, Санкт-Петербургский государственный экономический университет, наб. канала Грибоедова, 30-32, 191023 г. Санкт-Петербург, Россия, inkon_71@mail.ru, https://orcid.org/0000-0003-4903-5856

Татьяна Александровна Мельничук, доцент кафедры английской филологии, СевероВосточный федеральный университет им. М.К. Аммосова, ул. Белинского, 58, 677000 г. Якутск, Россия, melnichuk.ta@gmail.com, https://orcid.org/0000-0002-8126-0925 